\title{
A Novel Conflict Resolution Model Based on the Composition of Probabilistic Preferences
}

\author{
Annibal P. Sant'anna ${ }^{1}$, Ana Paula C. S. Costa ${ }^{2}$, \\ and Maisa M. Silva ${ }^{2(\bowtie)}$ \\ 1 Department of Management Engineering, Escola de Engenharia, \\ Universidade Federal Fluminense - UFF, Rua Passos da Pátria, \\ 156, São Domingos, Niterói, RJ 24210-240, Brazil \\ annibal.parracho@gmail.com \\ 2 Department of Management Engineering, Universidade Federal \\ de Pernambuco - UFPE, Caixa Postal 5125, Recife, PE 52070-970, Brazil \\ apcabral@hotmail.com, maisa@cdsid.org.br
}

\begin{abstract}
The purpose of this paper is to develop a four-stage conflict resolution model. In the first stage, a multicriteria model is developed for each of the conflicting parties, taken as decision makers (DMs) facing evaluations of a set of alternatives according to proper criteria. In the second stage, the composition of probabilistic preferences (CPP) methodology is applied to identify the best alternative for each of the conflicting parties. In the third stage, negotiation is carried out to remove alternatives and to focus on the subset of best alternatives for the group of DMs. The fourth stage consists of applying CPP again to choose one among the remaining alternatives. The model is illustrated by means of applying it to a real-world conflict in Brazil, related to implementation of the New Recife Project. The main features of the model are that it allows the DMs (i) to understand differences and proximities among the positions of each of them, (ii) to strategically reduce the initial set of alternatives, (iii) to advance in their positions towards a common goal, and (iv) to construct a unique final solution quickly.
\end{abstract}

Keywords: Composition of Probabilistic Preferences (CPP) $\cdot$ Conflict Resolution Model $\cdot$ Negotiation $\cdot$ Multicriteria

\section{Introduction}

The occurrence of conflicts, which are situations in which the actors involved present different perceptions and/or preferences, is very common within group decision and negotiation processes. The literature presents different methodologies to analyze this type of situation, among which are: Game Theory [1], Metagame Analysis [2], Conflict Analysis [3], and the Graph Model for Conflict Resolution (GMCR) [4, 5].

In this sense, the present paper advances in this area by proposing a methodology of analysis and resolution of conflicts, named Conflict Resolution Model with Composition of Probabilistic Preferences (CRMCPP), in which the decision process is divided 
into successive stages. Throughout this process, the Composition of Probabilistic Preferences (CPP) methodology [6] is applied to guide the evolution of the negotiators' positions.

The authors of [7] used CPP to deal with the presence of uncertainty in the assessment of preferences. Here, differently, CPP composition rules, based on the weighting of the criteria by the different negotiators, or other forms of joint evaluation, are used in the group decision context $[8,9]$. The solution can be defined by mutual agreement to determine an alternative that maximizes the joint preference. This may become difficult if there is disagreement among negotiators as to the positive or negative sense to be assigned to evaluations by one or more criteria. If this occurs, initially, guidelines to simplify positions are generated by applying CPP. Later, if negotiators do not reach full agreement, an automatic final solution is offered by re-applying CPP.

The main feature of CRMCPP is its ability to aid negotiators to understand differences and proximities between each other's positions, thereby allowing them to advance in their positions and to construct a final solution quickly. As a practical implication, the model proposed can be used in different real situations where a group of negotiators face difficulties in finding a consensual solution. The originality of this proposal is to simplify and accelerate the path of consensus by applying CPP.

This paper is structured as follows. Section 2 presents the CPP methodology and Sect. 3 the model of conflict resolution proposed using CPP. In Sect. 4, one real-world application of CRMCPP is presented using the data presented in [7]. Section 5 presents final considerations on the proposal, draws some conclusions and makes suggestions for future lines of research.

\section{Composition of Probabilistic Preferences (CPP)}

CPP is a methodology designed to take into account, in the composition of decision criteria, the presence of imprecision in the assessments of preference. By treating the evaluations as observations of random variables, it generates rules based on probabilities of choice to rank alternatives which are evaluated by different criteria or different experts. The first stage of applying CPP consists of associating a probability distribution to each evaluation of each alternative according to each criterion. The key idea is that each evaluation assessment determines a value around which it may vary. Instead of exact values, the evaluations are treated as location parameters of the probability distributions of possible values that would be assigned to the same alternative in other preference assessments under similar circumstances. Thus, the exact values of the decision matrix are turned into parameters of random variables.

On comparing these distributions, the probability that each alternative is the most preferred according to each criterion is accessed. This probability of an alternative being the most preferred is calculated as the joint probability of the set of multivariate evaluations for which such an alternative presents an evaluation higher than any other. To present this concept formally, let $\left(a_{i j}, \ldots, a_{n j}\right)$ denote a vector of evaluations of $n$ alternatives by a criterion $j$ and let $X_{k j}$ denote a random variable with the distribution of preference for the alternative $k$ according to criterion $j$. For any $k, a_{k j}$ will be used as a location parameter for the distribution of $X_{k j}$. The probability of alternative $i$ being the 
best according to criterion $j$ is given by the integral for $x$ varying along the domain of $X_{i j}$ of $P\left[X_{k j}<\mathrm{x}\right.$, for all $\left.k \neq i\right]$ with respect to the density of $X_{i j}$. Denoting by $f_{i}$ this density of the distribution of the evaluation of alternative $i$ by criterion $j$ and denoting by $F_{-i}$ the cumulative distribution function of the joint evaluations by criterion $j$ of the $n-1$ alternatives different from $i$, the probability of alternative $i$ being the most preferred by criterion $j$ is given by

$$
M_{i j}=\int F_{-i}(x) f_{i}(x) d x
$$

On the other hand, knowing the probabilities of being the least preferred is also useful. They are given by

$$
m_{i j}=\int\left(1-F_{-i}(x)\right) f_{i}(x) d x
$$

Applying proper composition rules from the probabilities of preference relative to each criterion may derive global probabilities of preference. The most employed composition rule explores the basic concepts of conditional probabilities. The probabilities of being the best alternative according to each criterion are then considered as conditional on the preference for such a criterion. Thus, an unconditional global preference is determined as a linear combination of these conditional probabilities. The preferences for the criteria enter as the marginal probabilities of the conditioning events that constitute the weights of the linear combination. The determination of these weights is difficult as interaction among criteria may have to be taken into account.

Simpler forms of composition consist of using probabilities of unions and intersections which are also permitted because of the probabilistic transformation. To use these forms of composition, instead of assigning weights to the criteria, the DM is asked only to choose between a conservative and a progressive point of view and between an optimistic and a pessimistic point of view. In the first choice, the progressive DM wants to decide on the basis of probabilities of maximizing the preference according to the criteria, while the conservative DM prefers to consider the probabilities of not minimizing it. The progressive DM pays attention to distances to the extremes of excellence, while the conservative one pays attention to distances to the extremes of worst performance. The term conservative is associated with risk aversion, while the term progressive refers to a DM who is willing to take risks in order to achieve a higher standard of excellence.

On the other hand, in the optimism versus pessimism choice, the optimistic point of view considers satisfactory being the best in at least one criterion or not being the worst in any of them. The global score is then determined by the probability of maximizing preference according to at least one among the multiple criteria or not minimizing preference according to all of them. Alternatively, from the pessimistic point of view, the global preference is measured by the probability of maximizing the preference according to all the criteria or not minimizing it with respect to any of them. The expressions optimistic and pessimistic are related to the idea of believing that the most 
favorable, or least favorable, criterion will prevail, respectively. Consequently, by combining these positions, four measures are generated:

$$
\begin{aligned}
& \text { Optimistic and conservative : } O C_{i}=1-\prod_{j} m_{i j} \\
& \text { Optimistic and progressive: } O P_{i}=1-\prod_{j}\left(1-M_{i j}\right) \\
& \text { Pessimistic and conservative : } P C_{i}=\prod_{j}\left(1-m_{i j}\right) \\
& \text { Pessimistic and progressive : } P P_{i}=\prod_{j} M_{i j}
\end{aligned}
$$

\section{Conflict Resolution Model Based on Composition of Probabilistic Preferences (CRMCPP)}

Two characteristics of CPP are explored in this paper with a view to resolving conflicts. First, there is the characteristic of implicitly assigning greater importance to the criteria with the greatest power to discriminate an option as the most preferred. Whatever the form of the multiple criteria used, the transformation of the initial evaluations into probabilities of being the most preferred increases the importance of those criteria that are most able to highlight a preferred option.

The second characteristic stems from the attention that CPP gives to the set of alternatives that are being compared in order to determine the context of the decision problem to be solved. As DMs who are also the negotiators reach agreement on which criteria adequately represent the opposing points of view, CPP can be used to help each negotiator eliminate the least preferred alternatives. By limiting the set of alternatives to those most preferred by at least one of the negotiators, the positions in conflict can be more clearly shown. Thus, it becomes easier for each negotiator to associate himself/herself with one or more of the others negotiators to reach a final decision in a space of simpler alternatives.

The decision problem is placed in terms of the search for an alternative that maximizes the joint preference with respect to the criteria maintained until the end. The alternative finally chosen is that one seen as providing the highest satisfaction not for a particular participant in the conflict but for the whole group. The group interest is represented by the set of criteria considered relevant by the end of the negotiation.

CPP is initially used to indicate to each negotiator a single alternative that best represents his/her own preferences. By examining these representative alternatives of the various positions, negotiators can identify close alternatives that, if they are kept competing with each other, will lessen the likelihood that each one of them will eventually be chosen. If, on the other hand, negotiators give up their own representatives and adhere to only one alternative to represent multiple negotiators, this will increase the probability that this will be the most preferred alternative in the last stage 
when CPP is applied for the final time. This encourages everybody to contribute towards simplifying the problem.

Any approach to the acceptance of the alternative that maximizes composite preference requires a preliminary stage of clear preference elicitation and negotiation that allows a set of preferred alternatives and preference criteria to be identified that are representative of the different interests. Therefore, a model for each negotiator is developed in the first stage. In the second stage, CPP is applied to each negotiator's criteria so as to identify an alternative that best represents him/her. In the third stage, the negotiators have the opportunity to unite, choosing only one among alternatives close to each other. In the last stage, CPP is applied to the set of remaining alternatives. Thus, CRMCPP is developed in four stages, as shown in Fig. 1.

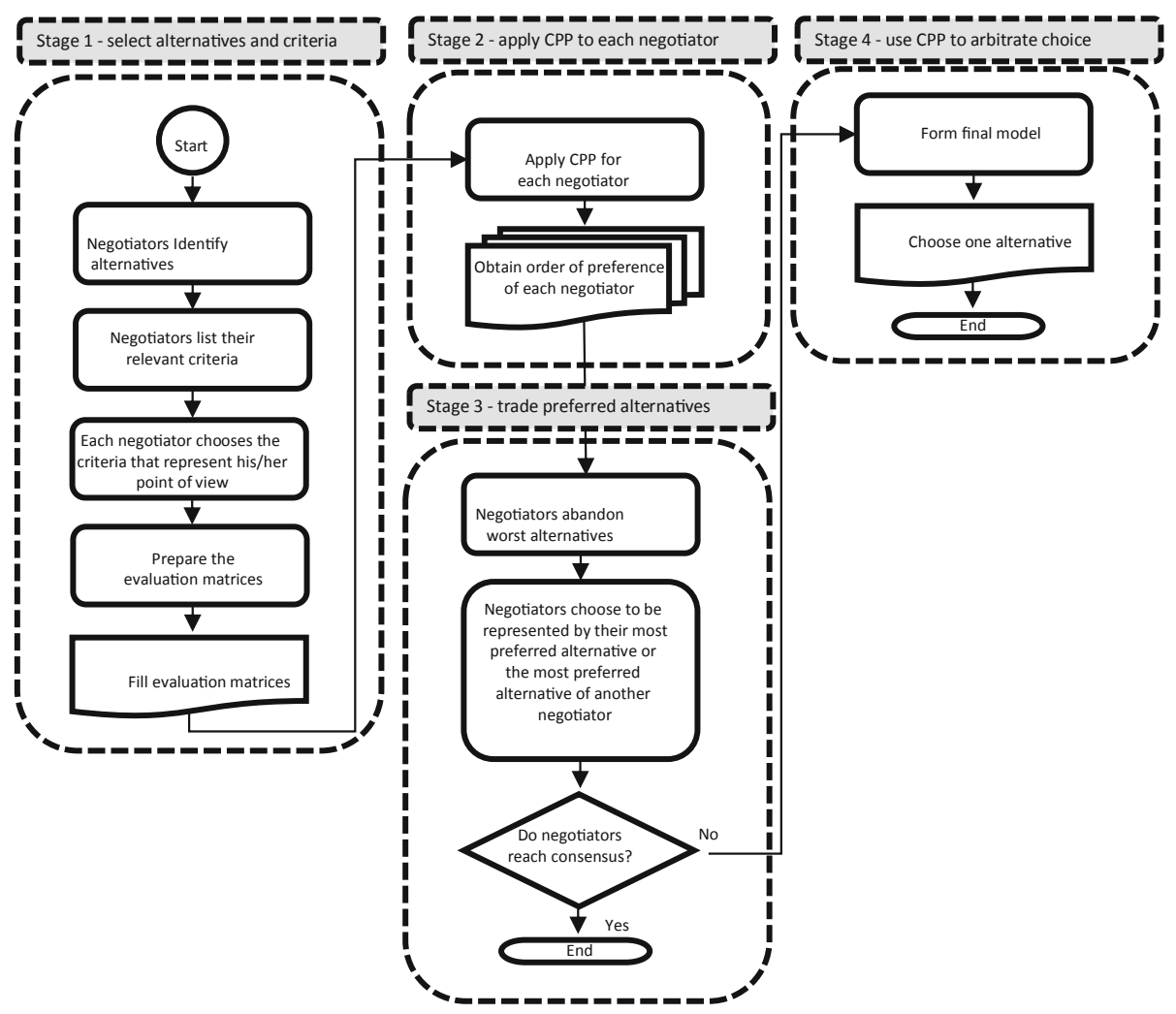

Fig. 1. Stages for applying the CRMCPP

In the second stage, the conservative pessimistic composition for each negotiator is applied, leading to the global evaluation by the joint probability of not minimizing the preference according to all the criteria in the model. This approach follows from the purpose of this stage is to identify an alternative that will represent the negotiator in the 
next stages. This alternative should have the lowest probability of misrepresentation in any aspect considered relevant by the negotiator.

In the fourth stage, considering that, if divergences remained until this point, it is impossible to fully satisfy all the negotiators, the form of combination used applies the optimistic and progressive point of view. The difficulty of reaching simultaneous satisfaction of conflicting criteria leads to the optimistic approach, in which one seeks to maximize the preference for at least one criterion, without establishing which one. And, assuming satisfaction maximization as the final goal, the conservative approach is replaced by the progressive one.

\section{Numerical Example}

The New Recife Project (NRP) is an urban project to reshape the area of the Jose Estelita Dock, in Recife, the capital of the Brazilian state of Pernambuco. The project is part of a plan to renew and revitalize the area. Revitalization plans for the area include the objective of attracting people to live in the area, most of which has had few residents for many years due to earlier redevelopments which, for a variety of reasons, drew the population of all social levels away. Over the last 20 years, one of the largest software development hubs in Brazil has been created in the historic downtown and even more recently the old port has been modernized both for sea-going trade and as an area of leisure and for cultural events. However, there is little residential housing, and so the conversion of the Dock area is seen as an opportunity for residential development.

Nevertheless, development plans have faced strong opposition for three main reasons. First, the balance between low-cost housing and homes for professionals is regarded by some as excessively favoring professionals and the interests of the developers. Secondly, some environmentalists claim that erecting residential towers will form a curtain that will cause the temperature of downtown to rise as the prevailing wind will no longer cool the area. Thirdly, some urbanists consider that residential towers will block landscape views of and from the city and that this would be a severe loss of an intangible asset that is central to the image of the sea-front of Recife.

The conflict is modeled in [7] as a dispute among three decision makers: NRP Support, NRP Opposition, and Recife Local Government (RLG). The NRP Support includes essentially a consortium of four private construction enterprises. The NRP opposition consists mainly of a protest movement called Occupy Estelita. The RLG includes the City Council and the Urban Development Council, a group consisting primarily of counselors representing the city and civil society.

The states of this conflict are represented by a set of four criteria, which measure in economic, environmental, social and political terms the impact expected. These four criteria have been determined by a group of six experts hired by RLG to evaluate the project. Two criteria (economic and political impacts) are measured in positive terms. In other words, they measure the benefits assuming that there is a possibility of the initiative being carried forward. The other two criteria measure the negative impacts of the initiative, should it be carried forward. The economic impact criterion is given by the approximate number of jobs created. The idea is that instead of making decisions 
unaided, the RLG decides to apply the conflict resolution technique presented in this paper. The four measures of impact are taken as decision criteria by all three negotiators. Initially, each negotiator compares the alternatives. In the final stage, the choice that is made is among the best alternatives for each negotiator.

It is assumed that the NRP consortium will choose one from three lines of action: proceed to complete the full NRP, proceed to finish the NRP with minor modifications, or proceed to finish the NRP with major modifications. The NRP Opposition may choose between not offering legal resistance or proceeding with a legal action against the NPR; and the RLG has four options, which are: support completion of full NRP, support completion of NRP with minor modifications, support completion of NRP with major modifications, and support suspension of the NRP. As the DMs cannot take their different actions simultaneously, this leads to a total of 24 combinations. A $25^{\text {th }}$ alternative is given by the status quo, with the project being fully developed, RLG selecting no option and no legal action being presented by the NRP opposition.

In Table 1, the three first rows correspond to the three options available to the consortium: full project, project with minor changes or project with major changes. The fourth row presents the only available option for the NRP Opposition which is to propose a legal action to prevent the construction of the project. In the four last rows, the options of the RLG are presented (full project, project with minor or major changes or the suspension of the project. In Table 1, a letter $\mathrm{Y}$ in the rows is the situation in which the option is chosen by the DM and the letter $\mathrm{N}$ represents the situation in which the option is not chosen by the DM.

Table 1. Options and feasible states in the NRP Conflict

\begin{tabular}{|c|c|c|c|c|c|c|c|c|c|c|c|c|c|}
\hline & 1 & 2 & 3 & 4 & 5 & 6 & 7 & 8 & 9 & 10 & 11 & 12 & 13 \\
\hline 1.1 Full & $\mathrm{Y}$ & $\mathrm{Y}$ & $\mathrm{N}$ & $\mathrm{N}$ & $\mathrm{Y}$ & $\mathrm{N}$ & $\mathrm{N}$ & $\mathrm{Y}$ & $\mathrm{N}$ & $\mathrm{N}$ & $\mathrm{Y}$ & $\mathrm{N}$ & $\mathrm{N}$ \\
\hline 1.2 Minor change & $\mathrm{N}$ & $\mathrm{N}$ & $\mathrm{Y}$ & $\mathrm{N}$ & $\mathrm{N}$ & $\mathrm{Y}$ & $\mathrm{N}$ & $\mathrm{N}$ & $\mathrm{Y}$ & $\mathrm{N}$ & $\mathrm{N}$ & $\mathrm{Y}$ & $\mathrm{N}$ \\
\hline 1.3 Major change & $\mathrm{N}$ & $\mathrm{N}$ & $\mathrm{N}$ & Y & $\mathrm{N}$ & $\mathrm{N}$ & $\mathrm{Y}$ & $\mathrm{N}$ & $\mathrm{N}$ & $\mathrm{Y}$ & $\mathrm{N}$ & $\mathrm{N}$ & $\mathrm{Y}$ \\
\hline 2. Legal action & $\mathrm{N}$ & $\mathrm{N}$ & $\mathrm{N}$ & $\mathrm{N}$ & $\mathrm{Y}$ & $\mathrm{Y}$ & $\mathrm{Y}$ & $\mathrm{N}$ & $\mathrm{N}$ & $\mathrm{N}$ & Y & $\mathrm{Y}$ & $\mathrm{Y}$ \\
\hline 3.1 Full support & $\mathrm{N}$ & $\mathrm{Y}$ & $\mathrm{Y}$ & Y & $\mathrm{Y}$ & $\mathrm{Y}$ & $\mathrm{Y}$ & $\mathrm{N}$ & $\mathrm{N}$ & $\mathrm{N}$ & $\mathrm{N}$ & $\mathrm{N}$ & $\mathrm{N}$ \\
\hline 3.2 Minor support & $\mathrm{N}$ & $\mathrm{N}$ & $\mathrm{N}$ & $\mathrm{N}$ & $\mathrm{N}$ & $\mathrm{N}$ & $\mathrm{N}$ & $\mathrm{Y}$ & $\mathrm{Y}$ & $\mathrm{Y}$ & $\mathrm{Y}$ & $\mathrm{Y}$ & $\mathrm{Y}$ \\
\hline 3.3 Major support & $\mathrm{N}$ & $\mathrm{N}$ & $\mathrm{N}$ & $\mathrm{N}$ & $\mathrm{N}$ & $\mathrm{N}$ & $\mathrm{N}$ & $\mathrm{N}$ & $\mathrm{N}$ & $\mathrm{N}$ & $\mathrm{N}$ & $\mathrm{N}$ & $\mathrm{N}$ \\
\hline \multirow[t]{2}{*}{ 3.4 Suspension } & $\mathrm{N}$ & $\mathrm{N}$ & $\mathrm{N}$ & $\mathrm{N}$ & $\mathrm{N}$ & $\mathrm{N}$ & $\mathrm{N}$ & $\mathrm{N}$ & $\mathrm{N}$ & $\mathrm{N}$ & $\mathrm{N}$ & $\mathrm{N}$ & $\mathrm{N}$ \\
\hline & 14 & 15 & 16 & 17 & 18 & 19 & 20 & 21 & 22 & 23 & 24 & 25 & \\
\hline 1.1 Full & Y & $\mathrm{N}$ & $\mathrm{N}$ & $\mathrm{Y}$ & $\mathrm{N}$ & $\mathrm{N}$ & Y & $\mathrm{N}$ & $\mathrm{N}$ & Y & $\mathrm{N}$ & $\mathrm{N}$ & \\
\hline 1.2 Minor change & $\mathrm{N}$ & $\mathrm{Y}$ & $\mathrm{N}$ & $\mathrm{N}$ & $\mathrm{Y}$ & $\mathrm{N}$ & $\mathrm{N}$ & $\mathrm{Y}$ & $\mathrm{N}$ & $\mathrm{N}$ & $\mathrm{Y}$ & $\mathrm{N}$ & \\
\hline 1.3 Major change & $\mathrm{N}$ & $\mathrm{N}$ & Y & $\mathrm{N}$ & $\mathrm{N}$ & $\mathrm{Y}$ & $\mathrm{N}$ & $\mathrm{N}$ & $\mathrm{Y}$ & $\mathrm{N}$ & $\mathrm{N}$ & $\mathrm{Y}$ & \\
\hline 2. Legal action & $\mathrm{N}$ & $\mathrm{N}$ & $\mathrm{N}$ & $\mathrm{Y}$ & $\mathrm{Y}$ & $\mathrm{Y}$ & $\mathrm{N}$ & $\mathrm{N}$ & $\mathrm{N}$ & $\mathrm{Y}$ & $\mathrm{Y}$ & $\mathrm{Y}$ & \\
\hline 3.1 Full support & $\mathrm{N}$ & $\mathrm{N}$ & $\mathrm{N}$ & $\mathrm{N}$ & $\mathrm{N}$ & $\mathrm{N}$ & $\mathrm{N}$ & $\mathrm{N}$ & $\mathrm{N}$ & $\mathrm{N}$ & $\mathrm{N}$ & $\mathrm{N}$ & \\
\hline 3.2 Minor support & $\mathrm{N}$ & $\mathrm{N}$ & $\mathrm{N}$ & $\mathrm{N}$ & $\mathrm{N}$ & $\mathrm{N}$ & $\mathrm{N}$ & $\mathrm{N}$ & $\mathrm{N}$ & $\mathrm{N}$ & $\mathrm{N}$ & $\mathrm{N}$ & \\
\hline 3.3 Major support & $\mathrm{Y}$ & $\mathrm{Y}$ & $\mathrm{Y}$ & Y & $\mathrm{Y}$ & Y & $\mathrm{N}$ & $\mathrm{N}$ & $\mathrm{N}$ & $\mathrm{N}$ & $\mathrm{N}$ & $\mathrm{N}$ & \\
\hline 3.4 Suspension & $\mathrm{N}$ & $\mathrm{N}$ & $\mathrm{N}$ & $\mathrm{N}$ & $\mathrm{N}$ & $\mathrm{N}$ & $\mathrm{Y}$ & $\mathrm{Y}$ & $\mathrm{Y}$ & $\mathrm{Y}$ & $\mathrm{Y}$ & $\mathrm{Y}$ & \\
\hline
\end{tabular}

Source. Adapted from [7] 
These alternatives (states for the conflict) are derived from positions ex ante, i.e. in a negotiation context, implementation prior to resolving the conflict. Due to the fact that the limitations eventually established by the authority ought to prevail and the desire of the proposers is to develop the project at the highest level allowed by the RLG, combinations with different levels of implementation allowed and proposed need not to be taken into account. In the same way, legal action by the Opposition need not be combined with the suspension of the project by the authority. Thus, from the 25 alternatives in Table 1, only alternatives 2, 5, 9, 12, 16, 19 and 20 need to be taken into account for the strategic analysis.

Indeed, Alternative 1 is a representation of the preliminary state of facts, without a position taken by the RLG. It is equivalent to allowing the full development of the project as contemplated by Alternative 2. Alternatives 3, 4, 6, 7, 8, 10, 11, 13, 14, 15, 17 and 18 need not be considered here because they present different levels of the proposal of the consortium and of support by the RLG. Nor need Alternatives 23, 24 and 25 be considered, because they combine suspension of the project by the authority with legal action by the opposition, legal action that becomes irrelevant if the initiative is not authorized. Therefore, the evaluations of the seven alternatives according to the four criteria, resulting from the assessments by the experts are given in Table 2. As above mentioned, applying the first two criteria the experts measure the benefits of the initiative being carried forward. On the other hand, the environmental and social impacts are considered on a basis of "the lower the better" by the RLG as well as by the NRP opposition.

Table 2. Evaluation matrix according to the four criteria

\begin{tabular}{c|l|l|l|l}
\hline Alternative & Economic & Environmental & Social & Political \\
\hline 2 & 8 & 4 & 5 & 7 \\
\hline 5 & 8 & 4 & 5 & 6 \\
\hline 9 & 6 & 3 & 2 & 6 \\
\hline 12 & 6 & 3 & 4 & 5 \\
\hline 16 & 2 & 2 & 2 & 5 \\
\hline 19 & 2 & 2 & 2 & 4 \\
\hline
\end{tabular}

Source. Adapted from [7].

Given its position and power of authority, RLG takes into account the four criteria, while two criteria are relevant for the Consortium and the Opposition. Therefore, the criteria that are considered by the consortium are those which have evaluations that increase with the level of support by the RLG, i.e. the level of the economic and political impacts. In fact, the economic impact measures the size of the project effectively implemented, coincident with the level of implementation decided by the consortium in Table 1. The inclusion of the political impact is considered because this is the only factor whose value in Table 2 is consistently reduced if legal action is taken by 
the opposition. Finally, those criteria which measure negative environmental and social impacts are chosen by the NRP Opposition.

Thus, in the second stage, for the RLG, the composition was by the joint probability of not minimizing the positive economic and political impacts and not maximizing the negative environmental and social impacts. For the NRP Consortium, by the probability of not minimizing the number of jobs created and the political impacts. For the NRP opposition, by the probability of not maximizing the harmful environmental and social impacts.

Since the evaluations result from the contribution of six experts, beta distributions are used. The probabilities of each alternative being the most preferred and the least preferred according to each criterion assuming beta distributions with means in the observed evaluations in Table 2 are presented in Tables 3 and 4.

Table 3. Probabilities of each alternative being the most preferred according to each criterion

\begin{tabular}{c|l|l|l|l}
\hline Alternative & Economic & Environmental & Social & Political \\
\hline 2 & 0.3967 & 0.3609 & 0.4346 & 0.452 \\
\hline 5 & 0.3967 & 0.3609 & 0.4346 & 0.1857 \\
\hline 9 & 0.0997 & 0.1112 & 0.0047 & 0.1857 \\
\hline 12 & 0.0997 & 0.1112 & 0.116 & 0.0718 \\
\hline 16 & 0.0035 & 0.0260 & 0.0047 & 0.0718 \\
\hline 19 & 0.0035 & 0.0260 & 0.0047 & 0.0252 \\
\hline 20 & 0.0003 & 0.0038 & 0.0005 & 0.0077 \\
\hline
\end{tabular}

Table 4. Probabilities of each alternative being the least preferred according to each criterion

\begin{tabular}{c|l|l|l|l}
\hline Alternative & Economic & Environmental & Social & Political \\
\hline 2 & 0.0012 & 0.0077 & 0.0008 & 0.0119 \\
\hline 5 & 0.0012 & 0.0077 & 0.0008 & 0.0400 \\
\hline 9 & 0.0099 & 0.0413 & 0.1521 & 0.0400 \\
\hline 12 & 0.0099 & 0.0413 & 0.0067 & 0.1047 \\
\hline 16 & 0.1852 & 0.1662 & 0.1521 & 0.1047 \\
\hline 19 & 0.1852 & 0.1662 & 0.1521 & 0.2333 \\
\hline 20 & 0.6074 & 0.5697 & 0.5356 & 0.4654 \\
\hline
\end{tabular}

Table 5 presents the results of the application of CPP in the second stage, using the Pessimist-Conservative (PC) approach, to choose one alternative to represent each DM in the next stage. For instance, the score 0.3566 of alternative 2 for RLG is the product of four factors, the probabilities of not maximizing the preference according to the environmental and social criteria, 1-0.3609 and 1- 0.4346, respectively, and the probabilities of not minimizing the preference according to the economic and political criteria, 1- 0.0012 and 1-0.0119, respectively. 
Table 5. Initial scores according to the three DMs

\begin{tabular}{c|l|l|l}
\hline Alternative & RLG & Consortium & Opposition \\
\hline 2 & 0.3566 & 0.9869 & 0.3613 \\
\hline 5 & 0.3464 & 0.9588 & 0.3613 \\
\hline 9 & 0.8409 & 0.9506 & 0.8846 \\
\hline 12 & 0.6966 & 0.8865 & 0.7857 \\
\hline 16 & 0.7072 & 0.7295 & 0.9694 \\
\hline 19 & 0.6055 & 0.6247 & 0.9694 \\
\hline 20 & 0.2090 & 0.2099 & 0.9957 \\
\hline
\end{tabular}

Therefore, the RLG most prefers Alternative 9, while the Consortium most prefers Alternative 2 and the Opposition most prefers Alternative 20. These three alternatives are then compared. The probabilities of maximizing the positive economic and political impacts and of minimizing the negative environmental and social impacts and, in the last column, the joint probabilities of maximizing the preference according to at least one of the four criteria, are presented in Table 6. For instance, the global score 0.9155 for alternative 2 is $1-(1-0.7425) *(1-0.0 .0277) *(1-0.0030) *(1-0.6616)$. As it can be seen, alternative 20 is the recommended one.

Table 6. Probabilistic evaluations and final scores for the three final alternatives

\begin{tabular}{c|l|l|l|l|l}
\hline Alternative & Economic & Environmental & Social & Political & Global \\
\hline 2 & 0.7425 & 0.0277 & 0.0030 & 0.6616 & 0.9155 \\
\hline 9 & 0.2545 & 0.1051 & 0.2545 & 0.3148 & 0.6592 \\
\hline 20 & 0.0030 & 0.8672 & 0.7425 & 0.0236 & 0.9667 \\
\hline
\end{tabular}

It is noticeable, nevertheless, that, according to the experts assessments in Table 1, Alternatives 2 and 9 are not very different from each other. Then in Stage 3, the Consortium might have agreed to the minor reduction of the project and withdrawn Alternative 2 to increase the chance of Alternative 9 in the final application of CPP. If that would have happened, this last alternative would have been chosen in the final stage.

\section{Conclusion and Final Remarks}

The application to the example showed that this methodology provides strategic ways to reduce the initial set of alternatives. This is especially important because the difficulties and effort involved in having to deal with a large number of alternatives is a known problem in complex conflict analysis. For instance, the authors of [10] point out that entering each DM's relative preferences over all feasible states is one of the most exacting challenges in the modelling stage of the GMCR. 
Moreover, a clear advantage of this new methodology is that it is able to provide unique solutions for a conflict, as observed in the example. This result must be highlighted because most conflict analysis models usually generate more than one possible result for the conflict. Therefore, these models usually require a negotiation process after the conflict analysis or resolution process is ended. The CRMCPP methodology involves both the conflict analysis and the negotiation processes throughout its four stages.

Another important point is that applying CPP at different stages of negotiation to conflict resolution provides an objective basis for negotiators to move forward in their positions. Besides, it facilitates the acceptance of a final solution that is built quickly on solid bases. The modelling of the problem in terms of the composition of quantitatively evaluated criteria and the composition of preferences in terms of the probability of preference facilitates being better able not only to understand the reasons for differences but also being better able to identify proximities between different positions.

The main limitation of the new model is that the quality of the results will depend decisively on the efficiency in the initial selection of the criteria and the evaluation of the alternatives according to the different criteria. However, the transformation of the initial data into probabilities of reaching the extremes of best and worst evaluation reduces the influence of errors of evaluation of less preferred alternatives and facilitates the interpretation of the data. For future research, it is suggested that the results of this new methodology be compared with equilibrium concepts of the GMCR.

\section{References}

1. Von Neumann, J., Morgenstern, O.: Theory of Games and Economic Behavior. Princeton University Press, Princeton (1944)

2. Howard, N.: Paradoxes of Rationality: Theory of Metagames and Political Behavior. MIT Press, Cambridge (1971)

3. Fraser, N.M., Hipel. K.W.: Conflict Analysis: Models and Resolutions. North-Holland, New York (1984)

4. Kilgour, D.M., Hipel, K.W., Fang, L.: The graph model for conflicts. Automatica 23(1), 4155 (1987)

5. Xu, H., Hipel, K.W., Kilgour, D.M., Fang, L.: Conflict Resolution Using the Graph Model: Strategic Interactions in Competition and Cooperation. SSDC, vol. 153. Springer, Cham (2018). https://doi.org/10.1007/978-3-319-77670-5

6. Sant'Anna, A.P.: Probabilistic Composition of Preferences, Theory and Applications. DE. Springer, Cham (2015). https://doi.org/10.1007/978-3-319-11277-0

7. Silva, M.M., Kilgour, D.M., Hipel, K.W., Costa, A.P.C.S.: Probabilistic composition of preferences in the graph model with application to the new recife project. J. Legal Aff. Dispute Resol. Eng. Constr. 9(3), 1-13 (2017)

8. Almeida, A.T., Morais, D.C., Daher, S.F.D.: Group Decision and Negotiation. Editora Universitária, Recife (2012)

9. Raiffa, H., Richardson, J., Matcalfe, D.: Negotiation Analysis: The Science and Art of Collaborative Decision Making. Harvard University Press, Cambridge (2002)

10. Yu, J., Hipel, K.W., Kilgour, D.M., Zhao, M.: Option prioritization for unknown preference. J. Syst. Sci. Syst. Eng. 25(1), 39-61 (2016) 